09,04

\title{
Спектральные и структурные характеристики ортоборатов $\mathrm{Lu}_{1-x-y} \mathrm{Ce}_{x} \mathrm{~Tb}_{y} \mathrm{BO}_{3}$, полученных методом гидротермального синтеза
}

\author{
(C) С.З. Шмурак, В.В. Кедров, А.П. Киселев, Т.Н. Фурсова, О.Г. Рыбченко \\ Институт фризики твердого тела РАН, \\ Черноголовка, Россия \\ E-mail: shmurak@issp.ac.ru
}

(Поступила в Редакцию 29 ноября 2016 г.)

\begin{abstract}
Проведены исследования структуры, ИК-спектров поглощения, морфологии и спектральных характеристик фотолюминесценции полученных методом гидротермального синтеза твердых растворов $\mathrm{Lu}_{1-x-y} \mathrm{Ce}_{x} \mathrm{~Tb}_{y} \mathrm{BO}_{3}$. Согласно данным рентгенофазового анализа, полученные в результате гидротермального синтеза при $T=200^{\circ} \mathrm{C}$ образцы $\mathrm{Lu}_{1-x-y} \mathrm{Ce}_{x} \mathrm{~Tb}_{y} \mathrm{BO}_{3}$ имеют структуру ватерита, и все дифракционные пики соответствуют гексагональной фазе с пр.гр. $P 6_{3} / m m c$, изоструктурной чистому $\mathrm{LuBO}_{3}$. Отжиг этих образцов при $T=970^{\circ} \mathrm{C}$ приводит к изменению структурной модификации и переходу образцов в моноклинную фазу с пространственной группой $C 2 / c$. Обнаружено, что после отжига этих образцов при $T=800-970^{\circ} \mathrm{C}$ интенсивность свечения ионов $\mathrm{Tb}^{3+}$ при возбуждении в полосе поглощения ионов $\mathrm{Ce}^{3+}$ увеличивается более чем на два порядка и становится значительно выше, чем в соединениях такого же состава, полученных при высокотемпературном синтезе. В то же время отжиг бората лютеция, легированного только тербием, не приводит к заметному изменению интенсивности свечения ионов $\mathrm{Tb}^{3+}$. Обсуждаются возможные причины многократного усиления свечения ионов тербия при отжиге полученного методом гидротермального синтеза ортобората лютеция, легированного церием и тербием.
\end{abstract}

DOI: 10.21883/FTT.2017.06.44487.426

\section{1. Введение}

Спектральные характеристики ортоборатов редкоземельных элементов (Р3Э) можно направленно изменять путем изменения их структурного состояния [1-4]. При этом существенную трансформацию претерпевают спектры люминесценции этих соединений. Спектры возбуждения люминесценции (СВЛ) боратов редкоземельных элементов радикально изменяются при осуществлении процесса переноса энергии от одних оптически активных центров к другим. Например, перенос энергии электронного возбуждения от $\mathrm{Ce}^{3+}$ к $\mathrm{Tb}^{3+}$ приводит к появлению в СВЛ ионов $\mathrm{Tb}^{3+}$ новой интенсивной полосы, совпадающей с полосой возбуждения ионов $\mathrm{Ce}^{3+}$ [4]. При этом спектральное положение этой полосы зависит от структурного состояния образца: ее максимумы в структурах кальцита и ватерита находятся при $\sim 339$ и $\sim 367 \mathrm{~nm}$ соответственно. Изменение количественного соотношения между фазами кальцита и ватерита в образце позволяет направленно изменять спектр возбуждения свечения ионов $\mathrm{Tb}^{3+}$, что важно для оптимизации спектральных характеристик $\mathrm{Lu}_{1-x-y} \mathrm{Ce}_{x} \mathrm{~Tb}_{y} \mathrm{BO}_{3}$ при его использовании в светодиодных источниках света. В работах [1-4] исследовались соединения, синтезированные в расплавах тетраборатов щелочных металлов или борного ангидрида. Для получения ватеритной модификации бората лютеция, легированного редкоземельными ионами, синтез проводился при $T=750-800^{\circ} \mathrm{C}$. Синтез кальцитной модификации осуществлялся при $T=970-1100^{\circ} \mathrm{C}$. В то же время получение боратов РЗЭ можно осуществлять гидротермальным синтезом при температурах $180-220^{\circ} \mathrm{C}$ в автоклаве [5-10]. Продуктом такого синтеза являются частицы шарообразной формы размером 5-10 $\mu \mathrm{m}$, состоящие из наноразмерных элементов, имеющих форму пластин. При этом определенная структурная модификация (кальцит или ватерит) может быть получена при разных величинах кислотности водной реакционной среды [7]. В работах [5-10] исследовались спектральные и структурные характеристики ортоборатов $\mathrm{LuBO}_{3}, \mathrm{YBO}_{3}$, легированных либо ионами $\mathrm{Eu}^{3+}$, либо ионами $\mathrm{Tb}^{3+}$. Согласно данным этих работ, спектральные характеристики образцов, полученных методом гидротермального и твердофазного синтеза, практически совпадают. Близки и интенсивности их свечения. Представляется целесообразным исследование переноса энергии между редкоземельными ионами $\mathrm{Ce}^{3+}$ и $\mathrm{Tb}^{3+}$ в полученных в результате гидротермального синтеза ортоборатах Р3Э.

В настоящей работе проведены исследования влияния отжига на спектральные и структурные характеристики полученных методом гидротермального синтеза твердых растворов состава $\mathrm{Lu}_{1-x-y} \mathrm{Ce}_{x} \mathrm{~Tb}_{y} \mathrm{BO}_{3}$. Обсуждаются возможные причины многократного усиления свечения ионов тербия при возбуждении в полосе поглощения ионов $\mathrm{Ce}^{3+}$ после отжига этих образцов.

\section{2. Методика эксперимента}

Для приготовления образцов твердых растворов ортоборатов редких земель с общей формулой $\mathrm{Lu}_{1-x-y} \mathrm{Ce}_{x} \mathrm{~Tb}_{y} \mathrm{BO}_{3}$ были использованы водные раство- 
ры нитратов РЗЭ, водный раствор аммиака и борная кислота. Раствор нитрата лютеция с концентрацией $2 \mathrm{M}$ получен растворением оксида лютеция $\mathrm{Lu}_{2} \mathrm{O}_{3}$ в концентрированной азотной кислоте с последующим удалением ее избытка путем выпаривания при длительном кипячении раствора. Для приготовления водных растворов азотно-кислых солей церия и тербия с концентрациями 0.02 и $0.25 \mathrm{M}$ соответственно были взяты твердые гидраты этих солей составов $\mathrm{Ce}\left(\mathrm{NO}_{3}\right)_{3} \cdot 6 \mathrm{H}_{2} \mathrm{O}$ и $\mathrm{Tb}\left(\mathrm{NO}_{3}\right)_{3} \cdot 5 \mathrm{H}_{2} \mathrm{O}$. Все использованные химические реактивы имели марку ЧДА.

Типичная синтетическая процедура состояла в следующем. К смеси водных растворов нитратов РЗЭ, взятых в необходимых количествах, добавлялась борная кислота со $100 \%$ избытком относительно стехиометрического состава. При этом общий объем раствора составлял $15 \mathrm{ml}$ (при концентрации $\mathrm{Lu}^{3+}$, равной $0.13-0.15 \mathrm{M}$ ). После этого в полученный раствор по каплям добавлялся водный раствор аммиака (25\% концентрации) до образования белого коллоидного осадка гидроокисей Р3Э и $\mathrm{pH}=9$. Полученная водная суспензия перемешивалась на магнитной мешалке в течение $20 \mathrm{~min}$, после чего она переливалась в тефлоновый стакан и помещалась на воздухе в металлический автоклав. После выдержки в автоклаве при $200^{\circ} \mathrm{C}$ в течение 24 или $72 \mathrm{~h}$ и последующего охлаждения продукт выделялся фильтрованием, промывался водой, спиртом и сушился при $80^{\circ} \mathrm{C}$ в течение $4 \mathrm{~h}$. При этом протекали следующие химические реакции:

$$
\begin{gathered}
\operatorname{Ln}\left(\mathrm{NO}_{3}\right)_{3}+3 \mathrm{NH}_{4} \mathrm{OH} \rightarrow \operatorname{Ln}(\mathrm{OH})_{3} \downarrow+3 \mathrm{NH}_{4} \mathrm{NO}_{3} \\
(L n=\mathrm{Lu}, \mathrm{Ce}, \mathrm{Tb}) \text { при } 20^{\circ} \mathrm{C}, \\
\operatorname{Ln}(\mathrm{OH})_{3}+\mathrm{H}_{3} \mathrm{BO}_{3} \rightarrow L n \mathrm{BO}_{3}+3 \mathrm{H}_{2} \mathrm{O} \\
(L n=\mathrm{Lu}, \mathrm{Tb}) \text { при } 200^{\circ} \mathrm{C}, \\
2 \mathrm{Ce}(\mathrm{OH})_{3}+1 / 2 \mathrm{O}_{2} \rightarrow 2 \mathrm{CeO}_{2} \downarrow+3 \mathrm{H}_{2} \mathrm{O} \\
\text { при } 200^{\circ} \mathrm{C} \text { и рН }=9 .
\end{gathered}
$$

Полученные образцы отжигались в течение $2 \mathrm{~h}$ на воздухе в интервале температур $200-1000^{\circ} \mathrm{C}$.

Рентгенодифракционные исследования образцов проводились с использованием дифрактометра SIEMENS D-500 (излучение $\mathrm{CuK}_{\alpha}$, первичный кварцевый монохроматор).

ИК-спектры поглощения измерялись на Фурье-спектрометре VERTEX 80v в спектральном диапазоне $400-5000 \mathrm{~cm}^{-1}$ с разрешением $2 \mathrm{~cm}^{-1}$. Для измерений поликристаллические порошки боратов перетирались в агатовой ступке, а затем тонким слоем наносились на кристаллическую шлифованную подложку $\mathrm{KBr}$.

Морфология образцов изучалась с использованием рентгеновского микроанализатора Supra 50VP с приставкой для EDS INCA (Oxford).

Спектры фотолюминесценции и спектры возбуждения люминесценции изучались на установке, состоя- щей из источника света - лампы ДКСШ-150, двух монохроматоров МДР-4 и МДР-6 (спектральный диапазон 200-1000 nm, дисперсия $1.3 \mathrm{~nm} / \mathrm{mm}$ ). Регистрация свечения осуществлялась с помощью фотоумножителя ФЭУ-106 (область спектральной чувствительности $200-800 \mathrm{~nm}$ ) и усилительной системы.

Спектральные и структурные характеристики, а также морфология образцов исследовались при комнатной температуре.

\section{3. Морфология образцов}

Полученные в результате гидротермального синтеза в течение $24 \mathrm{~h}$ образцы $\mathrm{Lu}_{1-x-y} \mathrm{Ce}_{x} \mathrm{~Tb}_{y} \mathrm{BO}_{3}$ являются частицами шарообразной формы диаметром $\sim 5 \mu \mathrm{m}$, которые в свою очередь состоят из нановолокон или наночешуек. Такую морфологию имеют все исследованные нами соединения ортоборатов $\mathrm{Lu}_{1-x-y} \mathrm{Ce}_{x} \mathrm{~Tb}_{y} \mathrm{BO}_{3}$. Последующий отжиг этих образцов в интервале температур $200-750^{\circ} \mathrm{C}$ не приводит к заметным изменениям их морфологии (рис. 1, a,c). Морфологические изменения исследуемых образцов начинают проявляться при температурах выше $800^{\circ} \mathrm{C}$. При этих температурах происходит плавление нановолокон/наночешуек с образованием более крупных частиц округлой формы диаметром 100-150 nm, которые соединены между собой. При этом формируется пористая структура, имеющая диаметр исходной сферической частицы (рис. $1, b, d$ ). Подобные сферические частицы наблюдались при гидротермальном синтезе ортоборатов иттрия [5].

Иную морфологию имеют образцы $\mathrm{Lu}_{1-x-y} \mathrm{Ce}_{x} \mathrm{~Tb}_{y} \mathrm{BO}_{3}$, полученные в результате гидротермального синтеза в течение $72 \mathrm{~h}$. Увеличение длительности гидротермального синтеза приводит к разрушению сферических частиц и укрупнению наночастиц. Такая картина сохраняется при отжиге образцов вплоть до температуры $800^{\circ} \mathrm{C}$. Дальнейшее повышение температуры отжига также приводит к плавлению наночастиц и их слиянию в более крупные образования округлой формы размером $300-600 \mathrm{~nm}$.

\section{4. Рентгеноструктурные исследования}

На рис. 2 представлена дифракционная картина исходного образца $\mathrm{Lu}_{0.845} \mathrm{Ce}_{0.005} \mathrm{~Tb}_{0.15} \mathrm{BO}_{3}$, полученного методом гидротермального синтеза при $200^{\circ} \mathrm{C}$ (время синтеза $24 \mathrm{~h}$ ). Все дифракционные линии индицируются в предположении гексагональной фазы, изоструктурной чистому $\mathrm{LuBO}_{3}$ (пространственная группа $P 6_{3} / m m c$ (194) (PDF-2, № 74-1938). Как видно из рисунка, дифракционные линии демонстрируют значительное уширение, не одинаковое для различных линий. Линии (002), (004), (104), (106) намного шире, чем (100), $(110),(200)$ (рис. 2 и вставка к нему). Подобный эффект наблюдался в работах $[5,8]$ и связывался с морфологией образца, в частности с квазидвумерностью образцов. 

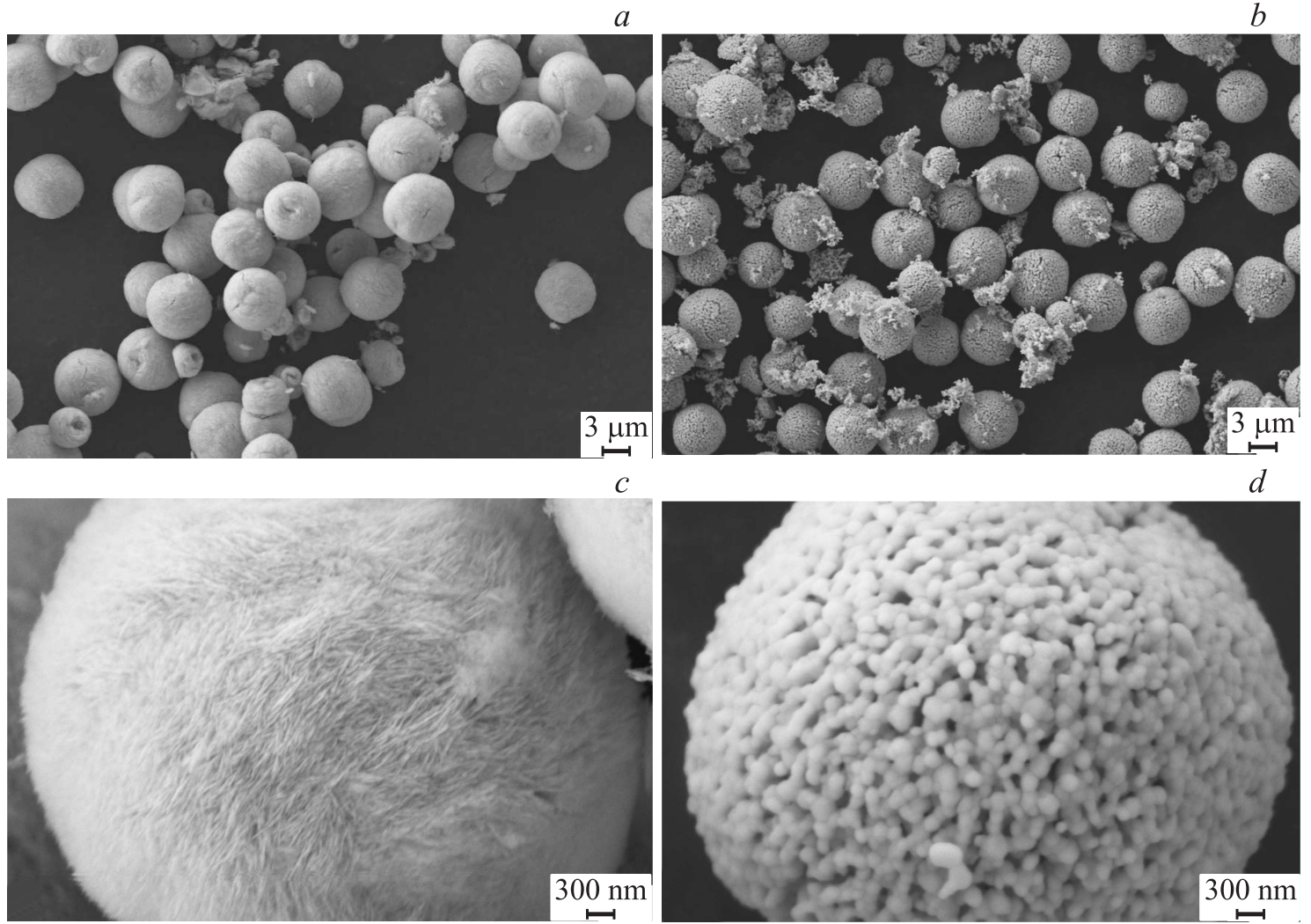

Рис. 1. Морфология соединения $\mathrm{Lu}_{0.845} \mathrm{Ce}_{0.005} \mathrm{~Tb}_{0.15} \mathrm{BO}_{3}$, полученного методом гидротермального синтеза при $200^{\circ} \mathrm{C}$ и отожженного при различных температурах. $a-d-$ время синтеза 24 h. $a, c-$ отжиг при $200^{\circ} \mathrm{C}, b, d-$ отжиг при $970^{\circ} \mathrm{C}$. Время отжига для всех образцов $2 \mathrm{~h}$.

И в нашем случае частицы, имеющие форму клубков, состоят из наночешуек толщиной $\sim 15-20 \mathrm{~nm}$ (рис. $1, c$ ).

Наблюдаемое уширение дифракционных линий, связанное с размерным эффектом, а также, вероятно, с некоторой дефектностью синтезированных частиц, за-

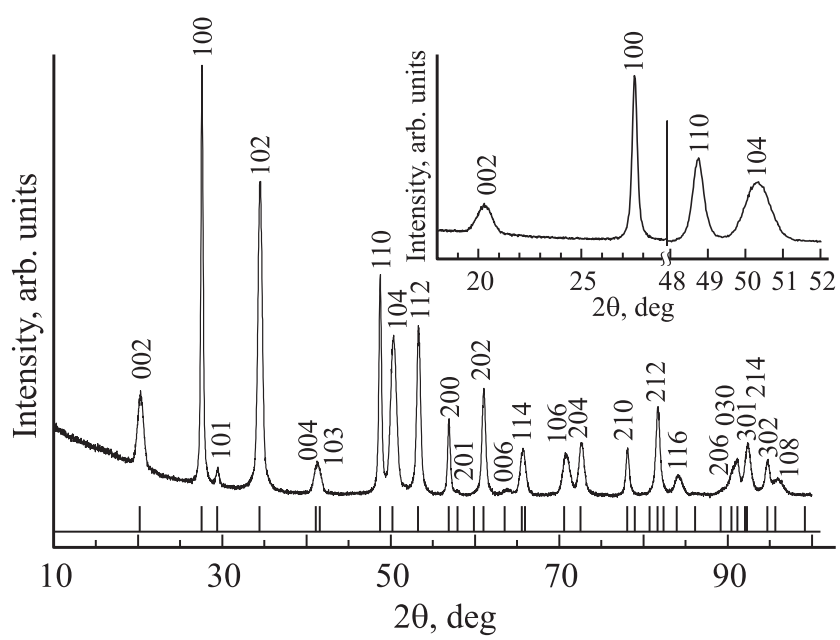

Pис. 2. Дифрактограмма соединения $\mathrm{Lu}_{0.845} \mathrm{Ce}_{0.005} \mathrm{~Tb}_{0.15} \mathrm{BO}_{3}$, полученного методом гидротермального синтеза, время синтеза $t=24 \mathrm{~h}$. На вставке - увеличенные фрагменты дифрактограммы, включающие рефлексы (002), (100), (110) и (104). трудняет определение кристаллической структуры. Действительно, наблюдаемый набор дифракционных линий можно также описать моноклинной решеткой, которая изоструктурна описанной в работах [11-13], в предположении, что уширение не позволяет разделить перекрывающиеся близкие линии. Таким образом, сделать выбор между двумя близкими структурами не представляется возможным.

Увеличение длительности синтеза приводит к сужению дифракционных линий, что позволяет идентифицировать структуру образца. На рис. 3 показана дифрактограмма синтезированного в течение $72 \mathrm{~h}$ образца $\mathrm{Lu}_{0.845} \mathrm{Ce}_{0.005} \mathrm{~Tb}_{0.15} \mathrm{BO}_{3}$ (кривая 1 ). Этот образец имеет гексагональную структуру, (пространственная группа $P 6_{3} / m m c$ (194), параметры кристаллической решетки $a=3.736 \AA$ и $c=8.780 \AA$ (см. таблицу).

Отжиг образцов при температуре $750^{\circ} \mathrm{C}$ в течение $2 \mathrm{~h}$ приводит к смещению некоторых дифракционных линий, связанному с изменением параметров ячейки и соответственно соотношения $c / a$ гексагональной решетки: $c / a=2.339$ (2.35 для исходного образца). Рассчитанные параметры ячейки $a=3.742 \AA, c=8.751 \AA$.

Отжиг образцов при температуре $970^{\circ} \mathrm{C}$ значительно изменяет как морфологию, так и структуру образца. На дифрактограмме (рис. 3, кривая 2) на- 
Структурные параметры образцов ортоборатов лютеция после гидротермального синтеза (72h) и после их отжига при $T=970^{\circ} \mathrm{C}(2 \mathrm{~h})$

\begin{tabular}{c|c|c}
\hline Состав & $\begin{array}{c}\text { Параметры элементарной ячейки исходного } \\
\left.\text { образца (гексагональная фаза, } P 6_{3} / m m c\right)\end{array}$ & $\begin{array}{c}\text { Параметры элементарной ячейки отожженного } \\
\text { образца (моноклинная фаза, } C 2 / c)\end{array}$ \\
\hline & $a=3.736(1) \AA$ & $a=11.217(2) \AA$ \\
$\mathrm{Lu}_{0.845} \mathrm{Ce}_{0.005} \mathrm{~Tb}_{0.15} \mathrm{BO}_{3}$ & $c=8.780(1) \AA$ & $b=6.484(1) \AA$ \\
& & $c=9.493(1) \AA$ \\
& & $\beta=112.84(2)^{\circ}$ \\
$\mathrm{Lu}_{0.85} \mathrm{~Tb}_{0.15} \mathrm{BO}_{3}$ & $a=3.737(1) \AA$ & $a=11.211(2) \AA$ \\
& $c=8.771(1) \AA$ & $b=6.478(1) \AA$ \\
& & $c=9.490(1) \AA$ \\
$\mathrm{Lu}_{0.995} \mathrm{Ce}_{0.005} \mathrm{BO}_{3}$ & & $\beta=112.89(1)^{\circ}$ \\
& $a=3.725(1) \AA$ & $a=11.187(2) \AA$ \\
& $c=8.749(1) \AA$ & $b=6.464(1) \AA$ \\
& & $c=9.474(1) \AA$
\end{tabular}

блюдается расщепление некоторых линий, появляются дополнительные отражения. Наиболее заметные изменения картины дифракции наблюдаются в области больших углов дифракции. На вставке к рис. 3
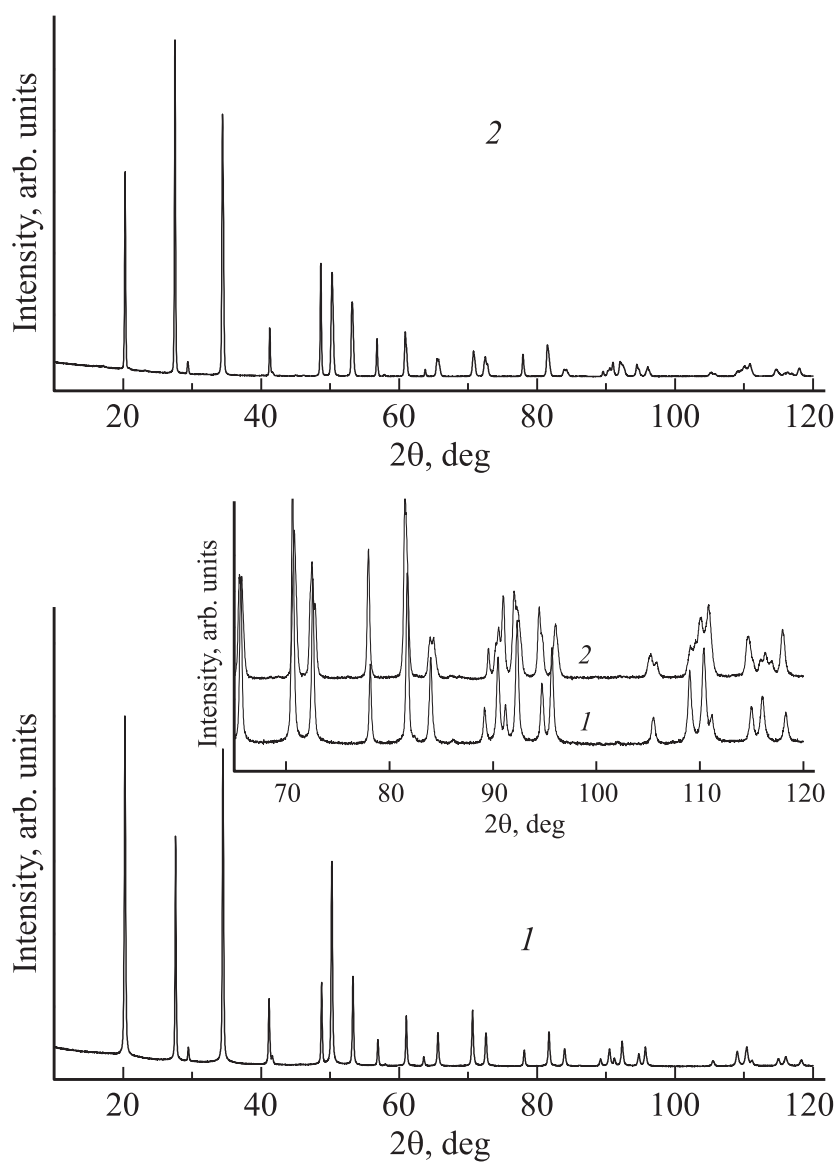

Рис. 3. Дифрактограммы соединения $\mathrm{Lu}_{0.845} \mathrm{Ce}_{0.005} \mathrm{~Tb}_{0.15} \mathrm{BO}_{3}$, полученного методом гидротермального синтеза, время синтеза $t=72 \mathrm{~h}$ : исходного (1) и отожженного при $T=970^{\circ} \mathrm{C}(2)$. На вставке - увеличенные фрагменты спектров 1 и 2. показаны дифрактограммы исходного и отожженного образцов $\mathrm{Lu}_{0.845} \mathrm{Ce}_{0.005} \mathrm{~Tb}_{0.15} \mathrm{BO}_{3}$ в интервале углов $2 \theta=65-120^{\circ}$. Полученная дифракционная картина описывается моноклинной решеткой с пространственной группой $C 2 / c$, наблюдавшейся ранее в ряде соединений, таких как $\mathrm{ErBO}_{3},\left(\mathrm{Y}_{0.92} \mathrm{Er}_{0.08}\right) \mathrm{BO}_{3}, \mathrm{GdBO}_{3}$ [11-13]. Pacсчитанные параметры кристаллической ячейки для образца $\mathrm{Lu}_{0.845} \mathrm{Ce}_{0.005} \mathrm{~Tb}_{0.15} \mathrm{BO}_{3}$ составляют $a=11.217 \AA$, $b=6.484 \AA, c=9.493 \AA, \beta=112.84^{\circ}$ (см. таблицу).

Аналогичные структурные изменения происходят в образцах $\mathrm{Lu}_{0.85} \mathrm{~Tb}_{0.15} \mathrm{BO}_{3}$ и $\mathrm{Lu}_{0.995} \mathrm{Ce}_{0.005} \mathrm{BO}_{3}$ после их отжига при $970^{\circ} \mathrm{C}$. Рассчитанные параметры ячеек исходной гексагональной и моноклинной фаз этих образцов представлены в таблице.

\section{5. ИК-спектры}

На рис. 4 приведены спектры поглощения в области внутренних колебаний связей $\mathrm{B}-\mathrm{O}$ исходного, полученного методом гидротермального синтеза (спектр 1) и отожженного при различных температурах (спектры 2-5) образца $\mathrm{Lu}_{0.845} \mathrm{Ce}_{0.005} \mathrm{~Tb}_{0.15} \mathrm{BO}_{3}$.

ИК-спектр исходного образца подобен спектрам образцов $\mathrm{Lu}_{0.85} \mathrm{~Tb}_{0.15} \mathrm{BO}_{3}$ и $\mathrm{Lu}_{0.94} \mathrm{Eu}_{0.06} \mathrm{BO}_{3}$, полученных в результате гидротермального синтеза в работах $[8,10]$. В каждом из спектров наблюдались три интенсивные полосы поглощения в спектральном диапазоне $800-1200 \mathrm{~cm}^{-1}$, характерном для валентных колебаний связей $\mathrm{B}-\mathrm{O}$ редкоземельных ортоборатов со структурой ватерита. В этой структуре три атома бора с тетраэдрическим окружением по кислороду образуют группу $\left(\mathrm{B}_{3} \mathrm{O}_{9}\right)^{9-}$ в виде трехмерного кольца. Результаты рентгеноструктурных исследований, проведенные в этих работах, показали, что образцы имеют структуру ватерита и все дифракционные пики соответствуют гексагональной фазе $\mathrm{LuBO}_{3}$ с пр.гр. $P 6_{3} / m m c$. 


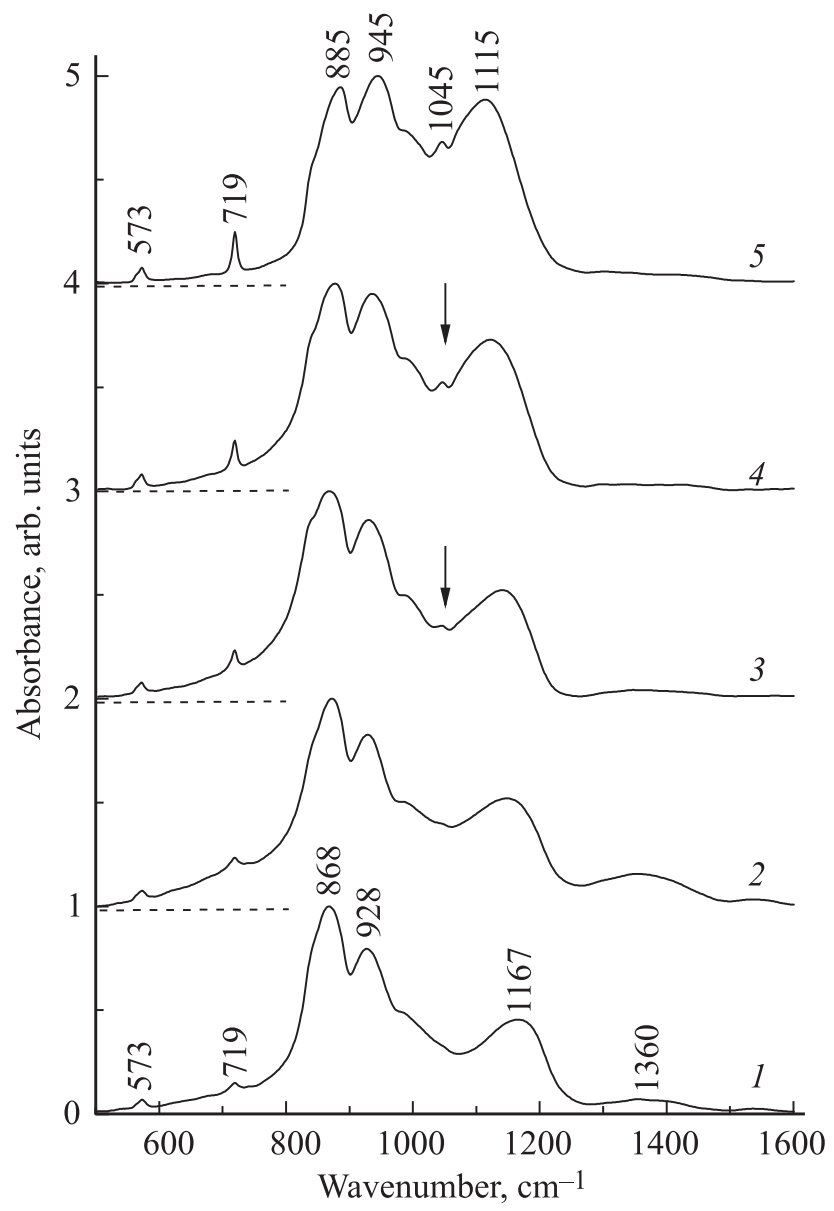

Рис. 4. ИК-спектры поглощения $\mathrm{Lu}_{0.845} \mathrm{Ce}_{0.005} \mathrm{~Tb}_{0.15} \mathrm{BO}_{3}$. 1 - исходный образец, $2-5-$ после отжига при температу$\operatorname{pax} 500,850,900$ и $970^{\circ} \mathrm{C}$ соответственно.

В ИК-спектре полученного в настоящей работе образца $\mathrm{Lu}_{0.845} \mathrm{Ce}_{0.005} \mathrm{~Tb}_{0.15} \mathrm{BO}_{3}$ (рис. 4, спектр 1) также наблюдаются аналогичные полосы поглощения (пики $\sim 868,928,1167 \mathrm{~cm}^{-1}$ ) в том же диапазоне $800-1200 \mathrm{~cm}^{-1}$, характерном для структуры ватерита. Полосы поглощения $868,928 \mathrm{~cm}^{-1}$ можно отнести к валентным колебаниям кольца группы $\left(\mathrm{B}_{3} \mathrm{O}_{9}\right)^{9-}$, а полосу $1167 \mathrm{~cm}^{-1}-$ к валентному колебанию терминальной связи В-О этой группы [14].

Широкую полосу $\sim 1360 \mathrm{~cm}^{-1}$ относят к валентным колебаниям $\mathrm{BO}_{3}$-групп, а полосы 573 и $719 \mathrm{~cm}^{-1}-$ к деформационным колебаниям $\mathrm{BO}_{4}$ - и $\mathrm{BO}_{3}$-групп $[8,10,15]$.

Спектр образца, отожженного при $T=970^{\circ} \mathrm{C}$ (рис. 4 , спектр 5), подобен спектрам поглощения соединений $\mathrm{Lu}_{1-x} R E_{x} \mathrm{BO}_{3}(R E=\mathrm{Eu}, \mathrm{Gd}, \mathrm{Tb}$, Dу и $\mathrm{Y} ; x=0.15-0.3)$, полученных при $T=970^{\circ} \mathrm{C}$ методом твердофазного синтеза [3] и имеющих структуру ватерита. Он содержит интенсивные полосы поглощения только в диапазоне $800-1200 \mathrm{~cm}^{-1}$ (пики $885,945,1045$ и $1115 \mathrm{~cm}^{-1}$ ), что свидетельствует о тетраэдрической координации атомов бора, характерной для структуры ватерита, и отсутствии других кристаллических фаз в образце.
Вместе с тем сравнение ИК-спектров этих образцов в области валентных колебаний связей $\mathrm{B}-\mathrm{O}$ показывает, что ИК-спектры исходного и отожженного при $970^{\circ} \mathrm{C}$ образцов (рис. 4, спектры 1 и 5) различаются тем, что в отожженном образце появляется новая линия $\sim 1045 \mathrm{~cm}^{-1}$, самая высокоэнергетическая полоса валентного колебания связи $\mathrm{B}-\mathrm{O} 1167 \mathrm{~cm}^{-1}$ сдвигается в низкоэнергетическую область до $1115 \mathrm{~cm}^{-1}$, а полосы 868 и $928 \mathrm{~cm}^{-1}$ - в область высоких энергий к 885 и $945 \mathrm{~cm}^{-1}$ соответственно. Кроме того, относительная интенсивность полосы поглощения $1167 \mathrm{~cm}^{-1}$ валентного колебания терминальной связи $\mathrm{B}-\mathrm{O}$ увеличивается, общая полуширина полосы валентных колебаний группы $\left(\mathrm{B}_{3} \mathrm{O}_{9}\right)^{9-}$ в диапазоне $800-1200 \mathrm{~cm}^{-1}$ уменьшается примерно на $50 \mathrm{~cm}^{-1}$. Появление в ИК-спектре новой полосы $\sim 1045 \mathrm{~cm}^{-1}$ связано скорее всего с тем, что, как показали рентгеновские исследования (раздел 4), отжиг образца $\mathrm{Lu}_{0.845} \mathrm{Ce}_{0.005} \mathrm{~Tb}_{0.15} \mathrm{BO}_{3}$ при $T=970^{\circ} \mathrm{C}$ приводит к изменению структурной модификации ватерита и переходу его из гексагональной симметрии с пространственной группой $P 6_{3} / m m c$ в моноклинную с пространственной группой $C 2 / c$. Кроме того, изменения в спектре 5 (рис. 4) свидетельствуют о более упорядоченной и более совершенной кристаллической структуре отожженного образца.

Исследование температурной зависимости спектра поглощения соединения $\mathrm{Lu}_{0.845} \mathrm{Ce}_{0.005} \mathrm{~Tb}_{0.15} \mathrm{BO}_{3}$ показало, что отжиги при $T=250-800^{\circ} \mathrm{C}$ не приводят к заметному изменению ИК-спектров. Перестройка спектра (появление новой линии при $\sim 1045 \mathrm{~cm}^{-1}$ и сужение полос) начинается после отжига при $T=850^{\circ} \mathrm{C}$ (рис. 4 , спектр 3) и усиливается при $T=900$ и $970^{\circ} \mathrm{C}$ (рис. 4 , спектры 4 и 5 ).

\section{6. Спектры люминесценции и спектры возбуждения люминесценции соединения $\mathrm{Lu}_{1-x-y} \mathrm{Ce}_{x} \mathrm{~Tb}_{y} \mathrm{BO}_{3}$}

6.1. Спектры люминесценци и. Интенсивность свечения ионов $\mathrm{Tb}^{3+}$ в образцах $\mathrm{Lu}_{1-x} \mathrm{~Tb}_{x} \mathrm{BO}_{3}$, полученных методом гидротермального синтеза, при возбуждении в полосах поглощения ионов $\mathrm{Tb}^{3+}$ практически не изменяется после отжига при $T=250-1000^{\circ} \mathrm{C}$ (рис. 5 кривая 1). В то же время интенсивность свечения ионов $\mathrm{Ce}^{3+}$ и $\mathrm{Tb}^{3+}$ в образцах ортобората лютеция, легированных одновременно 0.5 at.\% Се и 15 at.\% Tb, после отжига при $970^{\circ} \mathrm{C}$ увеличивается более чем на два порядка (рис. 5, кривые 3,4 ). Интенсивность свечения ионов $\mathrm{Ce}^{3+}$ в образцах $\mathrm{Lu}_{0.995} \mathrm{Ce}_{0.005} \mathrm{BO}_{3}$, отожженных при $970^{\circ} \mathrm{C}$, увеличивается в $20-50$ раз (рис. 5, кривая 2). Важно отметить, что спектры свечения ионов $\mathrm{Ce}^{3+}$ и $\mathrm{Tb}^{3+}$ в исходных и отожженных образцах совпадают.

Спектры люминесценции отожженных при $970^{\circ} \mathrm{C}$ образцов ортобората лютеция, легированных 0.5 at.\% Ce, 15 at.\% Tb и одновременно 0.5 at.\% Сe и 15 at. $\%$ Tb, представлены на рис. 6 (спектры 1-3). В спектрах лю- 
минесценции образцов $\mathrm{Lu}_{0.845} \mathrm{Ce}_{0.005} \mathrm{~Tb}_{0.15} \mathrm{BO}_{3}$ наблюдаются две широкие полосы с максимумами при $\sim 395$ и $\sim 425 \mathrm{~nm}$ и ряд узких полос, наиболее интенсивными из которых являются полосы 488,497 и $542.3 \mathrm{~nm}$ (рис. 6 , спектр 3). Полосы $\sim 395$ и $\sim 425 \mathrm{~nm}$, наблюдающиеся также в спектре люминесценции бората лютеция, легированного 0.5 at.\% Сe (рис. 6, спектр 1), соответствуют электронным переходам $4 f^{0} 5 d^{1} \rightarrow 4 f^{1}\left({ }^{2} F_{5 / 2}\right)$ и $4 f^{0} 5 d^{1} \rightarrow 4 f^{1}\left({ }^{2} F_{7 / 2}\right)$ в ионах $\mathrm{Ce}^{3+}$. Следует отметить, что такие же полосы наблюдаются в спектрах ватеритной модификации образцов бората лютеция, легированных церием, полученных методом твердофазного синтеза $[3,4,16,17]$. В диапазоне длин волн $450-570 \mathrm{~nm}$ спектры люминесценции образцов $\mathrm{Lu}_{0.845} \mathrm{Ce}_{0.005} \mathrm{~Tb}_{0.15} \mathrm{BO}_{3}$ и $\mathrm{Lu}_{0.85} \mathrm{~Tb}_{0.15} \mathrm{BO}_{3}$ (рис. 6, спектры 3 и2) совпадают. Они обусловлены свечением ионов $\mathrm{Tb}^{3+}$. Самая интенсивная полоса свечения находится при $\lambda_{\max }=542.3 \mathrm{~nm}$ (переход ${ }^{5} D_{4} \rightarrow{ }^{7} F_{5}$ ), что характерно для ватеритной модификации ортобората лютеция, легированного тербием $[3,4,8,18]$. Спектры люминесценции такие же, как для образцов ортобората лютеция, легированного 0.5 at.\% Ce и 15 at.\% Tb, наблюдаются для всех полученных нами методом гидротермального синтеза образцов $\mathrm{Lu}_{0.995-y} \mathrm{Ce}_{0.005} \mathrm{~Tb}_{y} \mathrm{BO}_{3}(0.05<y<0.2)$.

Следует отметить, что спектры люминесценции исследованных нами соединений $\mathrm{Lu}_{0.995-y} \mathrm{Ce}_{0.005} \mathrm{~Tb}_{y} \mathrm{BO}_{3}$, полученных методом гидротермального синтеза, не зависят от длины волны света, возбуждающего свечение либо поверхности образца $\left(\lambda_{\max }=274 \mathrm{~nm}\right.$, переход

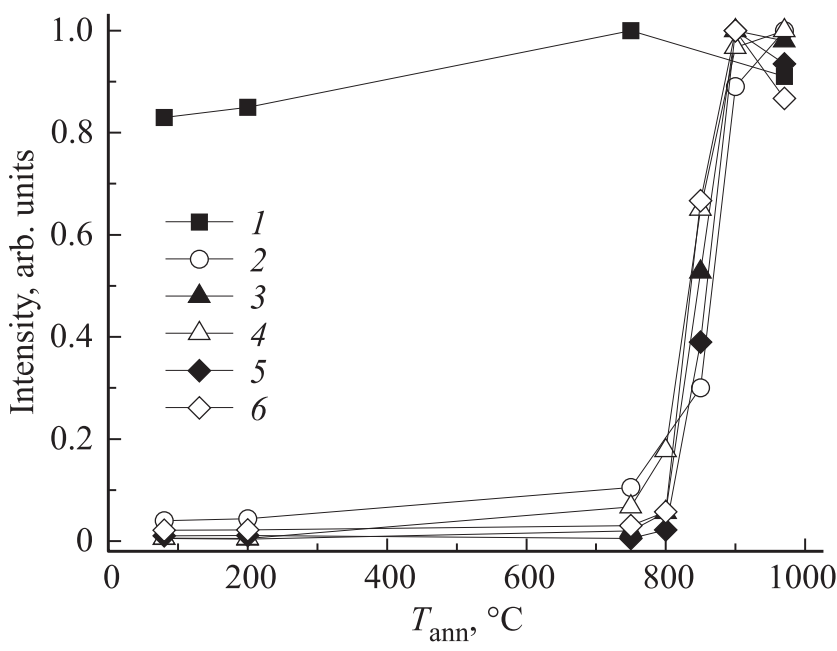

Рис. 5. Зависимости интенсивностей свечения одного из ионов $R E^{3+}\left(\mathrm{Ce}^{3+}, \mathrm{Tb}^{3+}\right)$ от температуры отжига соединений $\mathrm{Lu}_{1-x-y} \mathrm{Ce}_{x} \mathrm{~Tb}_{y} \mathrm{BO}_{3}$ и $\mathrm{Lu}_{0.85} \mathrm{~Tb}_{0.15} \mathrm{BO}_{3}+\mathrm{CeO}_{2} . \quad 1-$ интенсивность свечения $\mathrm{Tb}^{3+}\left(\lambda_{\max }=542.3 \mathrm{~nm}\right)$ в образце $\mathrm{Lu}_{0.85} \mathrm{~Tb}_{0.15} \mathrm{BO}_{3}$ при возбуждении светом $\lambda_{\mathrm{ex}}=274 \mathrm{~nm}, 3$ и 5 - интенсивности свечения $\mathrm{Tb}^{3+}\left(\lambda_{\max }=542.3 \mathrm{~nm}\right)$ в образцах $\mathrm{Lu}_{0.845} \mathrm{Ce}_{0.005} \mathrm{~Tb}_{0.15} \mathrm{BO}_{3}$ и $\mathrm{Lu}_{0.85} \mathrm{~Tb}_{0.15} \mathrm{BO}_{3}+\mathrm{CeO}_{2}$ соответственно при $\lambda_{\mathrm{ex}}=367 \mathrm{~nm}, 2,4$ и $6-$ интенсивности свечения $\mathrm{Ce}^{3+}\left(\lambda_{\max }=425 \mathrm{~nm}\right)$ в образцах $\mathrm{Lu}_{0.995} \mathrm{Ce}_{0.005} \mathrm{BO}_{3}$, $\mathrm{Lu}_{0.845} \mathrm{Ce}_{0.005} \mathrm{~Tb}_{0.15} \mathrm{BO}_{3}$ и $\mathrm{Lu}_{0.85} \mathrm{~Tb}_{0.15} \mathrm{BO}_{3}+\mathrm{CeO}_{2}$ соответственно при $\lambda_{\text {ex }}=367 \mathrm{~nm}$.

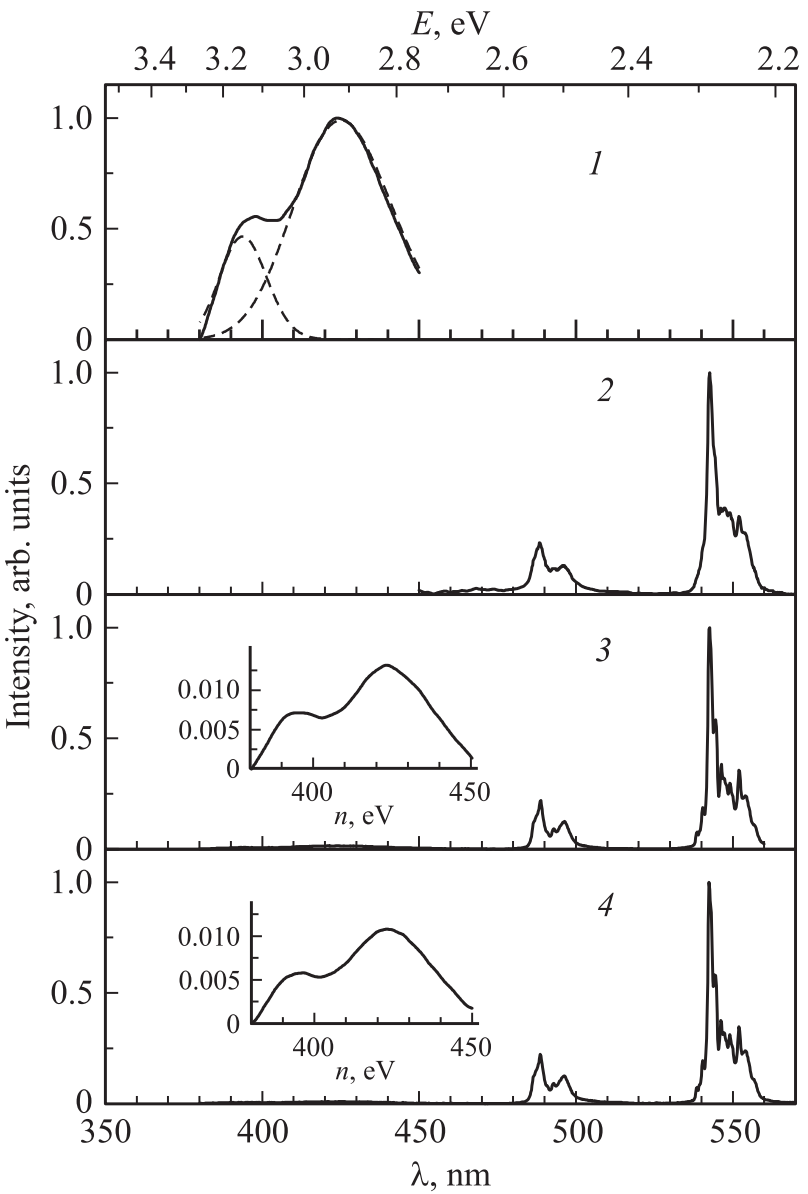

Рис. 6. Спектры люминесценции соединений $\mathrm{Lu}_{1-x-y} \mathrm{Ce}_{x} \mathrm{~Tb}_{y} \mathrm{BO}_{3}$ и $\mathrm{Lu}_{0.85} \mathrm{~Tb}_{0.15} \mathrm{BO}_{3}+\mathrm{CeO}_{2}$ после отжига при $970^{\circ} \mathrm{C} . \quad 1-x=0.005, \quad y=0, \quad \lambda_{\mathrm{ex}}=367 \mathrm{~nm} ; 2-$ $x=0, \quad y=0.15, \quad \lambda_{\mathrm{ex}}=274 \mathrm{~nm} ; 3-x=0.005, \quad y=0.15$, $\lambda_{\text {ex }}=367 \mathrm{~nm} ; 4-\mathrm{Lu}_{0.85} \mathrm{~Tb}_{0.15} \mathrm{BO}_{3}+\mathrm{CeO}_{2}$. На вставках приведены спектры люминесценции в диапазонах длин волн $380-450 \mathrm{~nm}$ (спектры 3 и 4) в увеличенном по оси ординат масштабе.

$4 f^{8} \rightarrow 4 f^{7} 5 d^{1}$ в ионе $\left.\mathrm{Tb}^{3+}[16]\right)$, либо его объема $\left(\lambda_{\max }=367 \mathrm{~nm}\right.$, переход $4 f^{1} \rightarrow 4 f^{0} 5 d^{1}$ в ионе $\left.\mathrm{Ce}^{3+}\right)$. Совпадение спектров люминесценции приповерхностного слоя и объема образцов свидетельствует о том, что ближний порядок вокруг ионов $\mathrm{Tb}^{3+}$ во всем объеме образцов одинаков, а значит, как показано в работах [19-21], образцы являются однофазными и имеют структуру типа ватерита. Это находится в согласии с данными рентгенофазового анализа и ИК-спектроскопии.

6.2. Спектры возбуждения люминесценци и. СВЛ ионов $\mathrm{Tb}^{3+}$ и $\mathrm{Ce}^{3+}$ в ортоборатах лютеция, полученных методом гидротермального синтеза и отожженных при $970^{\circ} \mathrm{C}$, содержащих 15 at. $\% \mathrm{~Tb}^{3+}$ или 0.5 at. $\% \mathrm{Ce}^{3+}$ и одновременно 15 at. $\% \mathrm{~Tb}^{3+}$ и 0.5 at. $\%$ $\mathrm{Ce}^{3+}$, представлены на рис. 7 (спектры 1-5). Спектр возбуждения люминесценции наиболее интенсивной полосы свечения соединения $\mathrm{Lu}_{0.845} \mathrm{Ce}_{0.005} \mathrm{~Tb}_{0.15} \mathrm{BO}_{3}$ $\left(\lambda_{\max }=542.3 \mathrm{~nm}\right), \quad$ которая обусловлена свечением 


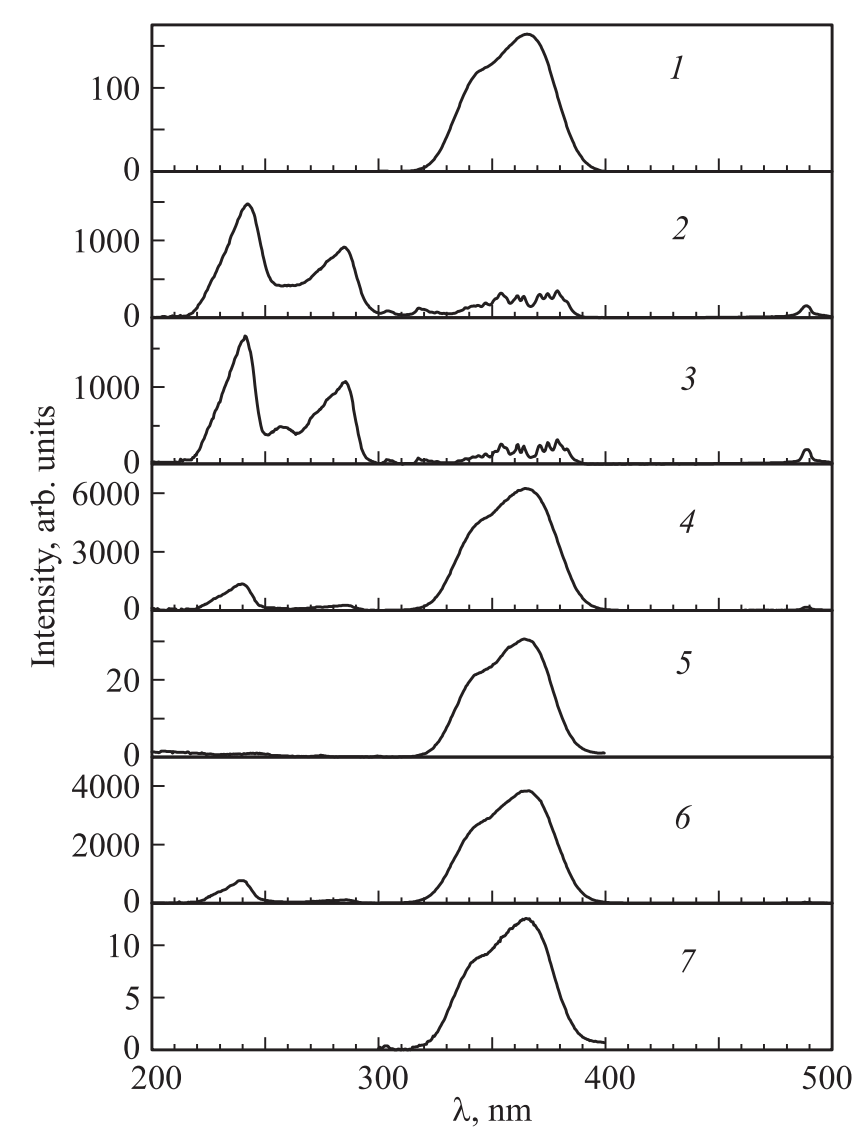

Рис. 7. Спектры возбуждения люминесценции отожженных при различных температурах соединений $\mathrm{Lu}_{1-x-y} \mathrm{Ce}_{x} \mathrm{~Tb}_{y} \mathrm{BO}_{3}$ и $\mathrm{Lu}_{0.85} \mathrm{~Tb}_{0.15} \mathrm{BO}_{3}+\mathrm{CeO}_{2} .1-x=0.005, y=0$, максимум свечения $\lambda_{\max }=425 \mathrm{~nm}, T_{\mathrm{ann}}=970^{\circ} \mathrm{C} ; 2-x=0$, $y=0.15, \lambda_{\max }=542.3 \mathrm{~nm}, T_{\mathrm{ann}}=200^{\circ} \mathrm{C} ; 3-x=0, y=0.15$, $\lambda_{\text {max }}=542.3 \mathrm{~nm}, \quad T_{\mathrm{ann}}=970^{\circ} \mathrm{C} ; 4-x=0.005, y=0.15$, $\lambda_{\max }=542.3 \mathrm{~nm}, \quad T_{\mathrm{ann}}=970^{\circ} \mathrm{C} ; 5-x=0.005, \quad y=0.15$, $\lambda_{\text {max }}=425 \mathrm{~nm}, T_{\text {ann }}=970^{\circ} \mathrm{C} ; 6-\mathrm{Lu}_{0.85} \mathrm{~Tb}_{0.15} \mathrm{BO}_{3}+\mathrm{CeO}_{2}$, $\lambda_{\max }=542.3 \mathrm{~nm}, T_{\mathrm{ann}}=900^{\circ} \mathrm{C} ; 7-\mathrm{Lu}_{0.85} \mathrm{~Tb}_{0.15} \mathrm{BO}_{3}+\mathrm{CeO}_{2}$, $\lambda_{\max }=425 \mathrm{~nm}, T_{\mathrm{ann}}=900^{\circ} \mathrm{C}$.

ионов $\mathrm{Tb}^{3+}$ (рис. 7, спектр 4), содержит полосы $\left(\lambda_{\mathrm{ex}} \sim 242,285\right.$ и $\left.489.5 \mathrm{~nm}\right)$, наблюдающиеся также в СВЛ ортобората лютеция, содержащего $15 \mathrm{at} \% \mathrm{~Tb}$ (рис. 7, спектры 2,3), и полосу $\left(\lambda_{\mathrm{ex}} \sim 367 \mathrm{~nm}\right)$. Полоса $367 \mathrm{~nm}$, имеющая наибольшую интенсивность, совпадает с полосой, наблюдающейся в СВЛ ионов $\mathrm{Ce}^{3+}\left(\lambda_{\max } \sim 425 \mathrm{~nm}\right)$, в $\mathrm{Lu}_{0.845} \mathrm{Ce}_{0.005} \mathrm{~Tb}_{0.15} \mathrm{BO}_{3}$ (рис. 7, спектр 5) и в СВЛ ортобората лютеция, содержащего только 0.5 at.\% Ce (рис. 7, спектр 1).

Таким образом, свечение ионов $\mathrm{Tb}^{3+}$ в соединении $\mathrm{Lu}_{0.845} \mathrm{Ce}_{0.005} \mathrm{~Tb}_{0.15} \mathrm{BO}_{3}$, отожженном при $970^{\circ} \mathrm{C}$, наблюдается при возбуждении образца светом, соответствующим максимуму возбуждения свечения ионов $\mathrm{Ce}^{3+}$ $\left(\lambda_{\mathrm{ex}}=367 \mathrm{~nm}\right)$. Приведенные экспериментальные факты однозначно свидетельствуют о том, что в этих образцах, как и в полученных методом твердофазного синтеза соединениях бората лютеция, легированных церием и тербием [4], перенос энергии электронного возбуждения от ионов $\mathrm{Ce}^{3+}$ к $\mathrm{Tb}^{3+}$ осуществляется в результате кулоновского диполь-дипольного взаимодействия [4].

Следует отметить, что спектр возбуждения люминесценции ионов $\mathrm{Tb}^{3+}\left(\lambda_{\max }=542.3 \mathrm{~nm}\right)$ в образцах $\mathrm{Lu}_{0.85} \mathrm{~Tb}_{0.15} \mathrm{BO}_{3}$, имеющих структуру типа ватерита, в области длин волн 320-390 nm содержит ряд узких резонансных полос (рис. 7, спектры 2,3). Однако их интенсивность ( $330 \mathrm{arb}$. units $)$ более чем на порядок меньше интенсивности свечения ионов $\mathrm{Tb}^{3+}$ в образцах $\mathrm{Lu}_{0.845} \mathrm{Ce}_{0.005} \mathrm{~Tb}_{0.15} \mathrm{BO}_{3}$ при возбуждении в полосе $367 \mathrm{~nm}$, которая составляет 6242 arb. units (рис. 7, спектр 4). Значительное увеличение свечения ионов $\mathrm{Tb}^{3+}$ в образцах $\mathrm{Lu}_{0.845} \mathrm{Ce}_{0.005} \mathrm{~Tb}_{0.15} \mathrm{BO}_{3}$ при возбуждении в полосе $367 \mathrm{~nm}$ происходит в результате переноса электронного возбуждения от ионов $\mathrm{Ce}^{3+}$ к ионам $\mathrm{Tb}^{3+}$.

Следует обратить внимание на то, что интенсивность свечения ионов $\mathrm{Ce}^{3+}$ при возбуждении светом, соответствующим максимуму полосы возбуждения $\mathrm{Ce}^{3+}$ $\left(\lambda_{\mathrm{ex}}=367 \mathrm{~nm}\right)$, в образцах бората лютеция, легированного только 0.5 at.\% Ce ( $I_{\mathrm{Ce}}=164$ arb. units) (рис. 7 , спектр 1), намного превосходит интенсивность свечения церия в борате лютеция, легированном одновременно и 0.5 at.\% Cе, и 15 at.\% Tb $\left(I_{\mathrm{Ce}+\mathrm{Tb}}=30\right.$ arb. units) (рис. 7, спектр 5). Уменьшение интенсивности свечения ионов $\mathrm{Ce}^{3+}$ в образцах, легированных одновременно и церием, и тербием, по сравнению с $I_{\mathrm{Ce}}$ в боратах лютеция, содержащих только Се, связано с переносом энергии электронного возбуждения от ионов $\mathrm{Ce}^{3+}$ к ионам $\mathrm{Tb}^{3+}$. Сравнивая интенсивности свечения ионов $\mathrm{Ce}^{3+}$ при отсутствии и наличии ионов $\mathrm{Tb}^{3+}$, можно определить эффективность переноса энергии от ионов $\mathrm{Ce}^{3+}$ к ионам $\mathrm{Tb}^{3+}$ с помощью соотношения

$$
\eta=\left(1-I_{\mathrm{Ce}+\mathrm{Tb}} / I_{\mathrm{Ce}}\right) \cdot 100 \%,
$$

где $I_{\mathrm{Ce}}$ и $I_{\mathrm{Ce}+\mathrm{Tb}}-$ интенсивности свечения $\mathrm{Ce}^{3+}$ в соединениях $\mathrm{Lu}_{0.995} \mathrm{Ce}_{0.005} \mathrm{BO}_{3}$ и $\mathrm{Lu}_{0.845} \mathrm{Ce}_{0.005} \mathrm{~Tb}_{0.15} \mathrm{BO}_{3}$ при возбуждении в максимуме свечения $\mathrm{Ce}^{3+}\left(\lambda_{\mathrm{ex}}=367 \mathrm{~nm}\right)$. Величина $\eta$ для соединения $\mathrm{Lu}_{0.845} \mathrm{Ce}_{0.005} \mathrm{~Tb}_{0.15} \mathrm{BO}_{3}$ в соответствии с приведенными выше данными равна $\sim 82 \%$, что свидетельствует о высокой эффективности процесса переноса энергии от $\mathrm{Ce}^{3+}$ к $\mathrm{Tb}^{3+}$ в соединении $\mathrm{Lu}_{0.845} \mathrm{Ce}_{0.005} \mathrm{~Tb}_{0.15} \mathrm{BO}_{3}$, полученном методом гидротермального синтеза и отожженном при $970^{\circ} \mathrm{C}$. Интересно отметить, что эффективность переноса энергии от $\mathrm{Ce}^{3+}$ к $\mathrm{Tb}^{3+}$ для ватеритной модификации $\mathrm{Lu}_{0.945} \mathrm{Ce}_{0.005} \mathrm{~Tb}_{0.05} \mathrm{BO}_{3}$, полученной методом твердофазного синтеза, составляет $\eta \sim 78 \%$ [4], а для соединения $\mathrm{Ba}_{3} \mathrm{Gd}\left(\mathrm{PO}_{3}\right)_{4}: \mathrm{Ce}^{3+}, \mathrm{Tb}^{3+}-78.6 \%[22]$.

Следует обратить внимание на то, что если спектры возбуждения свечения ионов $\mathrm{Ce}^{3+}$ исходных и отожженных при $970^{\circ} \mathrm{C}$ образцов совпадают, то в СВЛ ионов $\mathrm{Tb}^{3+}$ образцов $\mathrm{Lu}_{1-x} \mathrm{~Tb}_{x} \mathrm{BO}_{3}$, отожженных при $970^{\circ} \mathrm{C}$, появляется дополнительная слабая полоса с $\lambda_{\text {ex }}=258 \mathrm{~nm}$ (рис. 7, спектр 3). Наличие этой полосы в СВЛ образцов $\mathrm{Lu}_{1-x} \mathrm{~Tb}_{x} \mathrm{BO}_{3}$, как и полосы $\sim 1045 \mathrm{~cm}^{-1}$ в ИК-спектрах, может свидетельствовать о том, что такой образец имеет моноклинную решетку (пр.гр. $C 2 / c$ ). 
6.3. 3 ависимости интенсивностей свечения ионов $\mathrm{Tb}^{3+}$ и $\mathrm{Ce}^{3+}$ от температуры отжига ортоборатов лютеция, содержащих церий и тербий. Интенсивность свечения ионов $\mathrm{Tb}^{3+}$ в полученных методом гидротермального синтеза образцах бората лютеция, содержащих только тербий, при возбуждении в любой из полос, наблюдающихся в спектре возбуждения иона $\mathrm{Tb}^{3+}$, слабо зависит от температуры последующего отжига образца (рис. 5, кривая 1). Иная температурная зависимость интенсивности свечения ионов $\mathrm{Tb}^{3+}$ и $\mathrm{Ce}^{3+}$ при возбуждении в максимуме полосы возбуждения свечения $\mathrm{Ce}^{3+}\left(\lambda_{\mathrm{ex}}=367 \mathrm{~nm}\right)$ наблюдается при отжиге образцов ортобората лютеция, прекурсоры которых содержат церий и одновременно церий и тербий. В этих образцах интенсивности свечения $\mathrm{Ce}^{3+}{ }_{\text {в } \mathrm{LuBO}_{3}}$ : Се и $\mathrm{Tb}^{3+}$ и $\mathrm{Ce}^{3+}$ в $\mathrm{LuBO}_{3}: \mathrm{Ce}, \mathrm{Tb}$ незначительно увеличиваются при температурах отжига $200-750^{\circ} \mathrm{C}$, однако отжиг этих образцов при $800-900^{\circ} \mathrm{C}$ приводит к резкому и многократному увеличению интенсивностей свечения этих ионов (рис. 5, кривые 2-4). Например, в образцах бората лютеция с легирующими добавками 0.5 at.\% Се и 15 at.\% Тb интенсивности свечения $\mathrm{Tb}^{3+}$ и $\mathrm{Ce}^{3+}$ при $\lambda_{\mathrm{ex}}=367 \mathrm{~nm}$ увеличиваются соответственно от 29 и $0.15 \mathrm{arb}$. units в исходном образце до 6242 и $30 \mathrm{arb}$. units в отожженном при $900-970^{\circ} \mathrm{C}$ (рис. 7, спектры 4,5). Практически полное отсутствие свечения $\mathrm{Ce}^{3+}$ и слабая интенсивность свечения $\mathrm{Tb}^{3+}$ при возбуждении в полосе поглощения $\mathrm{Ce}^{3+}$ позволяют предположить, что в исходном кристалле бората лютеция концентрация $\mathrm{Ce}^{3+}$ пренебрежимо мала, однако после отжига при $T=970^{\circ} \mathrm{C}$ концентрация $\mathrm{Ce}^{3+}$ в этом кристалле увеличивается примерно на два порядка.

Следует обсудить еще одну возможную причину увеличения интенсивности свечения ионов $\mathrm{Ce}^{3+}$ после высокотемпературного отжига ортобората лютеция, легированного церием, а также тербием и церием одновременно. Согласно данным рентгенофазового анализа (раздел 4), при высокотемпературном отжиге $\left(T=900-970^{\circ} \mathrm{C}\right)$ происходит изменение структурного состояния ватеритной модификации исследуемых в настоящей работе ортоборатов лютеция. Полученные методом гидротермального синтеза образцы имеют гексагональную структуру, после высокотемпературного отжига их структура становится моноклинной. Можно предположить, что концентрация ионов $\mathrm{Ce}^{3+}$ при высокотемпературном отжиге не изменяется, а свечение увеличивается в результате изменения структурного состояния образца. Однако имеется ряд фактов, свидетельствующих о несостоятельности этого предположения. Свечение ионов $\mathrm{Ce}^{3+}$ в исследуемых нами образцах обусловлено разрешенными $4 f^{0} 5 d^{1} \rightarrow 4 f^{1}$ электронными переходами. Незначительные структурные перестройки, которые имеют место при переходе от гексагональной фазы ватерита к его моноклинной модификации, не оказывают практически никакого влияния даже на запрещенный переход ${ }^{5} D_{4} \rightarrow{ }^{7} F_{5}$ в ионах $\mathrm{Tb}^{3+}$. Действительно, как отмечалось выше, в
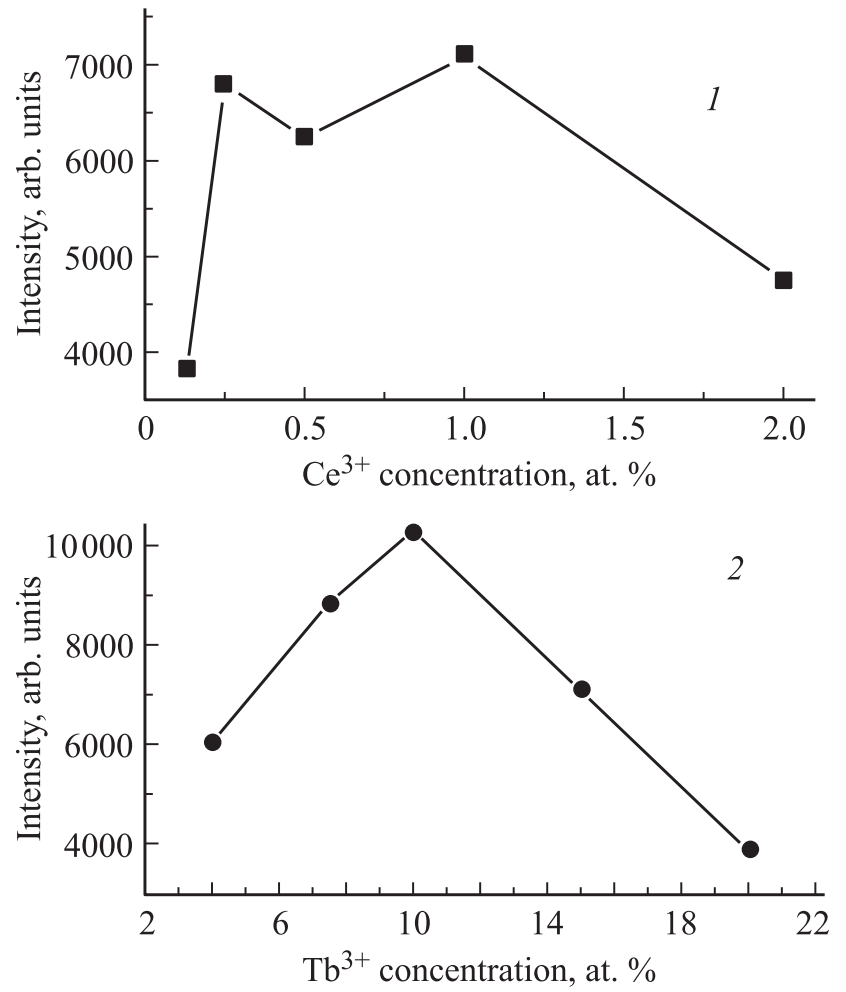

Рис. 8. Зависимости интенсивности свечения ионов $\mathrm{Tb}^{3+}$ $\left(\lambda_{\max }=542.3 \mathrm{~nm}\right)$ при возбуждении светом $\lambda_{\mathrm{ex}}=367 \mathrm{~nm} \mathrm{в}$ отожженных при $970^{\circ} \mathrm{C}$ соединениях $\mathrm{Lu}_{0.85-x} \mathrm{Ce}_{x} \mathrm{~Tb}_{0.15} \mathrm{BO}_{3}$ (1) и $\mathrm{Lu}_{0.99-y} \mathrm{Ce}_{0.01} \mathrm{~Tb}_{y} \mathrm{BO}_{3}(2)$.

полученных методом гидротермального синтеза образцах $\mathrm{LuBO}_{3}$ : Tb интенсивность свечения ионов тербия не зависит от температуры отжига вплоть до $T=970^{\circ} \mathrm{C}$. Поэтому переход от гексагональной фазы ватерита к его моноклинной модификации тем более не должен оказывать заметного влияния на интенсивность свечения ионов $\mathrm{Ce}^{3+}$, обусловленного разрешенными переходами. Кроме того, спектры люминесценции и спектры возбуждения люминесценции ионов $\mathrm{Ce}^{3+}$ для гексагональной и моноклинной модификаций ватерита идентичны, что свидетельствует об отсутствии влияния этих структурных перестроек на спектральные характеристики исследуемых образцов.

Изменение интенсивности свечения ионов $\mathrm{Tb}^{3+}$ $\left(\lambda_{\max }=542.3 \mathrm{~nm}\right)\left(I_{\mathrm{Tb}}\right)$ в зависимости от концентрации Се в образцах ортобората лютеция, содержащего 15 at.\% $\mathrm{Tb}$ и отожженного при $970^{\circ} \mathrm{C}$, при возбуждении в полосе поглощения $\mathrm{Ce}^{3+}\left(\lambda_{\mathrm{ex}}=367 \mathrm{~nm}\right)$ представлено на рис. 8 (кривая 1). Как видно из этого рисунка, максимум свечения ионов $\mathrm{Tb}^{3+}$ наблюдается при концентрации церия 1 at.\%. На рис. 8 (кривая 2) представлена зависимость $I_{\mathrm{Tb}}$ от концентрации тербия при фиксированной концентрации Ce 1 at.\%. Максимальная интенсивность свечения ионов $\mathrm{Tb}^{3+}$ при возбуждении в полосе поглощения $\mathrm{Ce}^{3+}$ наблюдается при концентрации тербия 10 at.\% и составляет 10250 arb. units. 
Как показано в работе [4], максимальная интенсивность свечения ионов $\mathrm{Tb}^{3+}$ в полученных методом твердофазного синтеза при $850^{\circ} \mathrm{C}$ образцах $\mathrm{Lu}_{0.945} \mathrm{Ce}_{0.005} \mathrm{~Tb}_{0.05} \mathrm{BO}_{3}$, имеющих структуру ватерита, при возбуждении в полосе поглощения ионов $\mathrm{Ce}^{3+}$ составляет 2350 arb. units. Интенсивность свечения ионов $\mathrm{Tb}^{3+}$ при $\lambda_{\mathrm{ex}}=367 \mathrm{~nm}$ в этих образцах, содержащих 70\% ватерита и $30 \%$ кальцита, составляет 4640 arb. units. Максимальная интенсивность свечения ионов тербия при возбуждении в полосе поглощения $\mathrm{Ce}^{3+}\left(\lambda_{\mathrm{ex}}=340 \mathrm{~nm}\right)$ наблюдается в полученных при $T=970^{\circ} \mathrm{C}$ образцах $\mathrm{Lu}_{0.945} \mathrm{Ce}_{0.005} \mathrm{~Tb}_{0.05} \mathrm{BO}_{3}$, имеющих структуру кальцита. В этих образцах $I_{\mathrm{Tb}}=6150$ arb. units [4]. Таким образом, интенсивность свечения ионов тербия при возбуждении в полосе поглощения ионов церия, обусловленного переносом энергии электронного возбуждения от $\mathrm{Ce}^{3+}$ к $\mathrm{Tb}^{3+}$ в образцах $\mathrm{Lu}_{0.89} \mathrm{Ce}_{0.01} \mathrm{~Tb}_{0.10} \mathrm{BO}_{3}$, полученных методом гидротермального синтеза и отожженных при $970^{\circ} \mathrm{C}$, имеющих структуру ватерита ( $I_{\mathrm{Tb}}=10250$ arb. units $)$, значительно превосходит $I_{\mathrm{Tb}}$ в содержащих Се и Ть ортоборатах лютеция, полученных в результате высокотемпературного синтеза и имеющих структуру ватерита или кальцита.

Обсудим возможные причины столь значительного увеличения интенсивности свечения при отжиге полученных методом гидротермального синтеза ортоборатов лютеция, содержащих церий и тербий. Как отмечалось, одна из легирующих добавок - тербий при гидротермальном синтезе замещает ионы лютеция. О вхождении тербия в решетку бората лютеция при легировании как $\mathrm{Tb}$, так и $\mathrm{Tb}+\mathrm{Ce}$ свидетельствуют также и данные рентгенофазового анализа, согласно которым происходит увеличение параметров решетки этих соединений по сравнению с параметрами решетки $\mathrm{LuBO}_{3}$ (для $\mathrm{LuBO}_{3}$ они равны $a=3.727 \AA, c=8.722 \AA$ (PDF-2, N 74-1938), а для бората лютеция, легированного 15 at.\% $\%$ и 15 at. $\% \mathrm{~Tb}+0.5$ at. $\% \mathrm{Ce}$, равны $a=3.737 \AA, c=8.771 \AA$ и $a=3.736 \AA, c=8.780 \AA$ соответственно). При этом отжиг образцов практически не изменяет интенсивности свечения тербия. При использовании двух легирующих добавок ( $\mathrm{Tb}$ и $\mathrm{Ce})$ в условиях гидротермального синтеза, по-видимому, только один тербий образует твердый раствор с боратом лютеция, а церий практически не входит в его решетку, поскольку не наблюдается свечение ионов $\mathrm{Ce}^{3+}$.

Для выяснения состояния церия при гидротермальном синтезе был проведен контрольный эксперимент с использованием в качестве исходных реагентов водной суспензии $\mathrm{Ce}(\mathrm{OH})_{3}(\mathrm{pH}=9)$ и борной кислоты. Методом рентгенофазового анализа было установлено, что продуктом этой реакции является двуокись церия $\left(\mathrm{CeO}_{2}\right)$.

Таким образом, можно предположить следующий порядок превращений, происходящих при гидротермальном синтезе и отжиге исследуемых соединений. Первой стадией гидротермального синтеза является реакция водных растворов нитратов РЗЭ со щелочью с образованием гидроокисей РЗЭ. Второй стадией синтеза, которая проходит при $T=200^{\circ} \mathrm{C}$, является взаимодействие гидроокисей $\mathrm{Lu}(\mathrm{OH})_{3}$ и $\mathrm{Tb}(\mathrm{OH})_{3}$ с борной кислотой с образованием твердого раствора $\mathrm{Lu}_{1-y} \mathrm{~Tb}_{y} \mathrm{BO}_{3}$. Гидроокись $\mathrm{Ce}(\mathrm{OH})_{3}$, как известно, в щелочной среде легко окисляется кислородом воздуха в автоклаве при температуре $200^{\circ} \mathrm{C}$, и образуется двуокись церия. Таким образом, продуктом гидротермального синтеза является смесь двух поликристаллических фаз: $\mathrm{Lu}_{1-y} \mathrm{~Tb}_{y} \mathrm{BO}_{3}$ и $\mathrm{CeO}_{2} ; \mathrm{Lu}_{1-y} \mathrm{~Tb}_{y} \mathrm{BO}_{3}$ образует шарообразные микрочастицы диаметром около $5 \mu \mathrm{m}$, состоящие из наноразмерных чешуек (пластинок) толщиной 15-20 nm (рис. $1, c$ ). Можно предположить, что $\mathrm{CeO}_{2}$ равномерно распределен среди чешуек $\mathrm{Lu}_{1-y} \mathrm{~Tb}_{y} \mathrm{BO}_{3}$. При температурах более $800^{\circ} \mathrm{C}$ высокая поверхностная энергия наночешуек $\mathrm{Lu}_{1-y} \mathrm{~Tb}_{y} \mathrm{BO}_{3}$ приводит к их плавлению, что повышает скорость диффузии ионов церия и вхождения их в $\mathrm{Lu}_{1-y} \mathrm{~Tb}_{y} \mathrm{BO}_{3}$ с образованием соединения $\mathrm{Lu}_{1-x-y} \mathrm{Ce}_{x} \mathrm{~Tb}_{y} \mathrm{BO}_{3}$.

В этом диапазоне температур процесс легирования церием соединения $\mathrm{Lu}_{1-y} \mathrm{~Tb}_{y} \mathrm{BO}_{3}$ проходит с высокой скоростью. Так, при отжиге при $970^{\circ} \mathrm{C}$ в течение 5 и $10 \mathrm{~min}$ интенсивности свечения тербия при возбуждении в полосе поглощения $\mathrm{Ce}^{3+}$ составляют соответственно 87 и 94\% от максимального значения.

О том, что при $800-970^{\circ} \mathrm{C}$ происходит плавление полученных гидротермальным методом наноразмерных чешуек ортобората лютеция, свидетельствуют данные морфологических исследований этой системы. Действительно, при температуре отжига $800-970^{\circ} \mathrm{C}$ наночешуйки начинают исчезать в результате их плавления и вследствие поверхностного натяжения возникают частицы сферической формы диаметром $\sim 100-150 \mathrm{~nm}$. Эти частицы, сплавленные друг с другом, сохраняют форму и внешний размер исходных микросфер (рис. 1,d).

Для проверки возможности осуществления процесса легирования соединения $\mathrm{Lu}_{1-y} \mathrm{~Tb}_{y} \mathrm{BO}_{3}$ диоксидом церия были проведены эксперименты по исследованию зависимости интенсивности свечения $\mathrm{Tb}^{3+}$ и $\mathrm{Ce}^{3+}$ при отжиге механической смеси соединений (98wt.\% Lu $\mathrm{Lu}_{1-y} \mathrm{~Tb}_{y} \mathrm{BO}_{3}$ и 2 wt.\% $\mathrm{CeO}_{2}$ ), полученных методом гидротермального синтеза, в интервале температур $T_{\text {ann }}=200-970^{\circ} \mathrm{C}$. Как видно из рис. 5 (кривые 5,6), эти зависимости полностью совпадают с аналогичными зависимостями для соединений $\mathrm{Lu}_{0.995} \mathrm{Ce}_{0.005} \mathrm{BO}_{3}$ и $\mathrm{Lu}_{0.845} \mathrm{Ce}_{0.005} \mathrm{~Tb}_{0.15} \mathrm{BO}_{3}$. Резкий рост интенсивностей свечения $\mathrm{Tb}^{3+}$ и $\mathrm{Ce}^{3+}$ происходит в относительно узком интервале температур $800-900^{\circ} \mathrm{C}$. Следует отметить, что при отжиге смеси соединений (98wt.\% $\mathrm{Lu}_{1-y} \mathrm{~Tb}_{y} \mathrm{BO}_{3}$ и 2 wt.\% $\mathrm{CeO}_{2}$ ) максимальное значение интенсивности свечения $\mathrm{Tb}^{3+}\left(\lambda_{\max }=542.3 \mathrm{~nm}\right) \quad\left(I_{\mathrm{Tb}}\right)$ при возбуждении в полосе поглощения $\mathrm{Ce}^{3+}\left(\lambda_{\mathrm{ex}}=367 \mathrm{~nm}\right)$ наблюдается при $T_{\mathrm{ann}}=900^{\circ} \mathrm{C}$. Величина $I_{\mathrm{Tb}}$ равна $4026 \mathrm{arb}$. units, что сопоставимо со значением интенсивности свечения $\mathrm{Lu}_{0.845} \mathrm{Ce}_{0.005} \mathrm{~Tb}_{0.15} \mathrm{BO}_{3}$, полученного методом гидротермального синтеза и отожженного при $900-970^{\circ} \mathrm{C}$ (6242 arb. units). Это свидетельствует о том, что эффективность процесса легирования $\mathrm{Lu}_{1-y} \mathrm{~Tb}_{y} \mathrm{BO}_{3}$ диок- 
сидом церия является высокой даже в неблагоприятных условиях взаимодействия реагентов, находящихся в виде механической смеси порошков. Следует также отметить, что спектры люминесценции (рис. 6, спектр 4) и спектры возбуждения люминесценции (рис. 7, спектры 6,7) механической смеси порошков, отожженных при 900-970 ${ }^{\circ}$, совпадают с аналогичными спектрами полученных методом гидротермального синтеза соединений $\mathrm{Lu}_{1-x-y} \mathrm{Ce}_{x} \mathrm{~Tb}_{y} \mathrm{BO}_{3}$ после отжига при $970^{\circ} \mathrm{C}$ (рис. 6, кривая 3; рис. 7, кривые 4,5).

Такие же, как для соединений $\mathrm{Lu}_{1-x-y} \mathrm{Ce}_{x} \mathrm{~Tb}_{y} \mathrm{BO}_{3}$, закономерности изменения спектров люминесценции и спектров возбуждения люминесценции наблюдались нами при отжиге полученных в результате гидротермального синтеза образцов ортобората иттрия, содержащего Се и $\mathrm{Tb}$. Например, в образцах $\mathrm{Y}_{0.845} \mathrm{Ce}_{0.005} \mathrm{~Tb}_{0.15} \mathrm{BO}_{3}$ интенсивности свечения $\mathrm{Tb}^{3+}$ и $\mathrm{Ce}^{3+}$ при $\lambda_{\mathrm{ex}}=367 \mathrm{~nm}$ увеличиваются соответственно от 2 и 0.5 arb. units в исходном образце до 7192 и 18 arb. units в образце, отожженном при $970^{\circ} \mathrm{C}$.

\section{7. Заключение}

В настоящей работе проведены исследования структуры, ИК-спектров поглощения, спектральных характеристик и морфологии полученных методом гидротермального синтеза и отожженных при температурах 200-970 ${ }^{\circ} \mathrm{C}$ твердых растворов бората лютеция, активированных церием и тербием. Наиболее значимыми являются следующие результаты.

1. Обнаружено, что при отжиге полученных гидротермальным синтезом образцов $\mathrm{Lu}_{1-x-y} \mathrm{Ce}_{x} \mathrm{~Tb}_{y} \mathrm{BO}_{3}$ при $T=800-970^{\circ} \mathrm{C}$ интенсивность свечения ионов $\mathrm{Tb}^{3+}$ при возбуждении в доминирующей в спектре возбуждения ионов тербия полосе $\left(\lambda_{\mathrm{ex}}=367 \mathrm{~nm}\right)$ увеличивается более чем на два порядка. Совпадение этой полосы с полосой возбуждения ионов $\mathrm{Ce}^{3+}$ свидетельствует о том, что свечение ионов тербия происходит в результате переноса энергии от $\mathrm{Ce}^{3+} \kappa \mathrm{Tb}^{3+}$, который осуществляется по механизму кулоновского диполь-дипольного взаимодействия между церием и тербием (ферстеровский механизм переноса энергии). В то же время отжиг образцов $\mathrm{LuBO}_{3}: \mathrm{Tb}$, не содержащих церия, не приводит к заметному изменению интенсивности свечения ионов $\mathrm{Tb}^{3+}$. Многократное увеличение интенсивности свечения ионов тербия, происходящее в исследуемых образцах при их отжиге при $T=800-970^{\circ} \mathrm{C}$, является следствием значительного увеличения концентрации ионов $\mathrm{Ce}^{3+}$ в образцах в результате диффузии ионов $\mathrm{Ce}$ при плавлении наночешуек $\mathrm{LuBO}_{3}: \mathrm{Tb}$ и образования соединения $\mathrm{Lu}_{1-x-y} \mathrm{Ce}_{x} \mathrm{~Tb}_{y} \mathrm{BO}_{3}$.

2. Согласно данным рентгенофазового анализа, образцы бората лютеция, легированного церием, тербием и одновременно церием и тербием, имеют структуру ватерита и все дифракционные пики соответствуют гексагональной фазе, изоструктурной чистому
$\mathrm{LuBO}_{3}$ с пр.гр. $P 6_{3} / m m c$. Отжиг этих образцов при $T=970^{\circ} \mathrm{C}$ приводит к изменению структурной модификации ватерита и переходу его в моноклинную фазу с пространственной группой $C 2 / c$. В спектре ИКпоглощения отожженных при $970^{\circ} \mathrm{C}$ образцов появляется линия $\sim 1045 \mathrm{~cm}^{-1}$, а в спектре возбуждения люминесценции ионов $\mathrm{Tb}^{3+}$ слабая полоса $\lambda_{\mathrm{ex}}=258 \mathrm{~nm}$. Они могут служить индикаторами возникновения моноклинной модификации образца.

3. Максимальная интенсивность свечения полученных в результате гидротермального синтеза и отожженных при $970^{\circ} \mathrm{C}$ образцов $\mathrm{Lu}_{1-x-y} \mathrm{Ce}_{x} \mathrm{~Tb}_{y} \mathrm{BO}_{3}$ наблюдается при концентрации Сe 1 at.\% и Тb 10 at.\% и составляет 10250 arb. units, что в $\sim 1.7$ раза превосходит интенсивность свечения образцов кальцитной модификации $\mathrm{Lu}_{1-x-y} \mathrm{Ce}_{x} \mathrm{~Tb}_{y} \mathrm{BO}_{3}$, полученных методом твердофазного синтеза, и интенсивность свечения промышленного зеленого люминофора $\mathrm{Y}_{2} \mathrm{O}_{2} \mathrm{~S}: \mathrm{Tb}$. Высокая интенсивность свечения образцов $\mathrm{Lu}_{1-x-y} \mathrm{Ce}_{x} \mathrm{~Tb}_{y} \mathrm{BO}_{3}$ обусловлена высокой эффективностью переноса энергии от ионов $\mathrm{Ce}^{3+}$ к $\mathrm{Tb}^{3+}$. Экспериментально показано, что в отожженных при $970^{\circ} \mathrm{C}$ образцах $\mathrm{Lu}_{0.845} \mathrm{Ce}_{0.005} \mathrm{~Tb}_{0.15} \mathrm{BO}_{3}$ перенос энергии от $\mathrm{Ce}^{3+}$ к $\mathrm{Tb}^{3+}$ осуществляется с эффективностью 82\%.

Полученные методом твердофазного синтеза образцы кальцитной модификации $\mathrm{Lu}_{1-x-y} \mathrm{Ce}_{x} \mathrm{~Tb}_{y} \mathrm{BO}_{3}$ являются хорошо ограненными микрокристаллами, средний размер которых составляет $\sim 10 \mu \mathrm{m}$, в то же время исследуемые в настоящей работе образцы представляют собой микросферы диаметром $\sim 5 \mu \mathrm{m}$, состоящие из сплавленных частиц сферической формы диаметром $\sim 100-150 \mathrm{~nm}$.

4. Многократное увеличение интенсивности свечения ионов тербия наблюдалось нами также и в других ортоборатах, легированных церием и тербием, полученных методом гидротермального синтеза и отожженных при $T=900-970^{\circ} \mathrm{C}$. Например, в отожженном при $970^{\circ} \mathrm{C}$ образце $\mathrm{Y}_{0.845} \mathrm{Ce}_{0.005} \mathrm{~Tb}_{0.15} \mathrm{BO}_{3}$ интенсивность свечения $\mathrm{Tb}^{3+}$ при $\lambda_{\mathrm{ex}}=367 \mathrm{~nm}$ составляет 7192 arb. units.

Учитывая высокую интенсивность свечения, радиационную, химическую стабильность и высокую теплопроводность ортоборатов, соединение $\mathrm{Lu}_{0.89} \mathrm{Ce}_{0.01} \mathrm{~Tb}_{0.10} \mathrm{BO}_{3}$ может рассматриваться в качестве эффективного зеленого люминофора для светодиодных источников света.

Авторы выражают благодарность Е.Ю. Постновой за исследование морфологии образцов, Н.Ф. Прокопюку за помощь в проведении экспериментов.

\section{Список литературы}

[1] С.З. Шмурак, В.В. Кедров, А.П. Киселев, И.И. Зверькова. ФTT 55, 336 (2013).

[2] С.З. Шмурак, В.В. Кедров, А.П. Киселев, И.М. Шмытько. ФTT 57, 19 (2015).

[3] С.3. Шмурак, В.В. Кедров, А.П. Киселев, Т.Н. Фурсова, И.М. Шмытько. ФТТ 57, 1558 (2015). 
[4] С.З. Шмурак, В.В. Кедров, А.П. Киселев, Т.Н. Фурсова, И.М. Шмытько. ФТТ 58, 564 (2016).

[5] X.C. Jiang, L.D. Sun, C.H. Yan. J. Phys. Chem. B 108, 3387 (2004).

[6] J. Ma, Q. Wu, Y. Ding, Y. Chen. Cryst. Growth. Design 7, 1553 (2007).

[7] J. Yang, C.X. Li, X.M. Zhang, Z.W. Quan, C.M. Zhang, H.Y. Li, J. Lin. Chem. Eur. J. 14, 4336 (2008).

[8] J. Yang, C.M. Zhang, L.L. Wang, Z.Y. Hou, S.S. Huang, H.Z. Lian, J. Lin. J. Solid St. Chem. 181, 2672 (2008).

[9] Y.P. Li, J.H. Zhang, X. Zhang, Y.S. Luo, S.Z. Lu, X,G. Ren, X.J. Wang, L.D. Sun, C.H. Yan. Chem. Mater. 21, 468 (2009).

[10] J. Yang, H.G. Zhang, Z.L. Wang, C.Z. Huang, L. Zou, P. Cai, Y.F. Zhang, S.S. Hu. J. Mater. Sci. 48, 2258 (2013).

[11] A. Pitscheider, R. Kaindl, O. Oeckler, H. Huppertz. J. Solid St. Chem. 184, 149 (2011).

[12] J.H. Lin, D. Sheptyakov, Y.X. Wang, P. Allenspach. Chem. Mater. 16, 2418 (2004).

[13] A. Szczeszak, T. Grzyb, S. Lis, R.J. Wiglusz. Dalton Trans. 41, 5824 (2012).

[14] Z.G. Wei, L.D. Sun, C.S. Liao, J.L. Yin, X.C. Jiang, C.H. Yan, S.Z. Lu. J. Phys. Chem. B 106, 10610 (2002).

[15] Z.J. Zhang, T.T. Jin, M.M. Xu, Q.Z. Huang, M.R. Li, J.T. Zhao. Inorg. Chem. 54, 969 (2015).

[16] M.J. Weber, S.E. Derenso, C. Dujardin. Proc. of SCINT $95 /$ Eds P. Dorenbos, C.W.E. van Eijk. Delft, The Netherlands (1996). P. 325.

[17] N.V. Klassen, S.Z. Shmurak, I.M. Shmyt'ko, G.K. Strukova, S.E. Derenso, M.J. Weber. Nucl. Instrum. Method. Phys. Res. A 537, 144 (2005).

[18] C. Mansuy, J.M. Nedelec, C. Dujardin, R. Mahiou. Opt. Mater. 29, 697 (2007)

[19] А.П. Киселев, С.З. Шмурак, Б.С. Редькин, В.В. Синицын, И.М. Шмытько, Е.А. Кудренко, Е.Г. Понятовский. ФТТ 48, 1458 (2006).

[20] S.Z. Shmurak, A.P. Kiselev, N.V. Klassen, V.V. Sinitsyn, I.M. Shmyt'ko, B.S. Red'kin, S.S. Khasanov. IEEE Trans. Nucl. Sci. 55, 1128 (2008).

[21] С.3. Шмурак, А.П. Киселев, Д.М. Курмашева, Б.С. Редькин, В.В. Синицын. ЖЭТФ 137, 867 (2010).

[22] Y. Jin, Y. Hu, Li Chen, X. Wang, Z. Mu, G. Ju, Z. Yang. Physica B 436, 105 (2014). 